\title{
A STATISTICAL ANALYSIS OF HIP SCORES
}

\author{
M. J. BRYANT, W. G. KERNOHAN, J. R. NIXON, R. A. B. MOLLAN
}

From Musgrave Park Hospital, Belfast, Northern Ireland

Thirteen methods of hip scoring were applied in the postoperative assessment of 47 hip arthroplasties. Their results were found to be inconsistent, often giving contrary measures of success in the same patient.

Ten variables were measured during the postoperative review of 256 hip arthroplasties and the data were submitted to multivariate factor analysis. This revealed that the ten variables could be reduced to three factors: pain, which correlated poorly with any other variable (Spearman correlation, $\mathrm{r}<0.02$ ); functional activity (distance walked, use of walking aids, stair climbing, use of public transport, limp, sitting and tying shoelaces); and deformity and range of movement. The range of hip flexion correlated closely with the sum of the arcs of movement and with Gade's index (Spearman correlation, $r>0.9$ ).

We suggest that, for outcome assessment, only three variables need to be recorded: pain, walking distance and range of hip flexion. The combination of these three measures into a single hip score is misleading.

J Bone Joint Surg [Br] 1993; 75-B :705-9.

Received 29 September 1992; Accepted after revision 20 April 1993

As a method of quantifying the benefits of treatment, hip scores owe their importance to the success of hip arthroplasty and to the recent interest in health economics. The variables measured by most hip scores include pain, range of movement, walking distance, use of walking aids, presence or absence of a limp, ability to tie shoelaces, climb stairs, sit in a low chair and work, and the Trendelenburg sign. Patient satisfaction and radiological changes indicative of prosthetic loosening are also sometimes included.

There are at least 19 different methods of calculating a hip score (Table I). Each variable can be expressed as 'excellent', 'good', 'fair' or 'bad' and the overall assessment can be given in similar terms. Alternatively, the

M. J. Bryant, MD, FRCS, FRCS Orth, Senior Orthopaedic Registrar W. G. Kernohan, PhD, FIMA, CMath, Lecturer in Biotechnology

J. R. Nixon, MCh Orth, FRCS, FRCS I, Consultant Orthopaedic Surgeon

R. A. B. Mollan, MD, FRCS, FRCS I, Professor of Orthopaedic Surgery

Department of Orthopaedic Surgery, Musgrave Park Hospital, Stockmans Lane, Belfast BT9 7JB, UK.

Correspondence should be sent to Mr M. J. Bryant.

C1993 British Editorial Society of Bone and Joint Surgery $0301-620 \mathrm{X} / 93 / 5649 \$ 2.00$ variables can be measured on a point system and expressed either singly or as their sum. The score is then given as a percentage of the maximum possible number of points. Judet and Judet (1952) subtracted the preoperative from the postoperative values to give an 'amelioration rate' for hip arthroplasty.

Most scores weigh pain heavily as the most important variable although there is a wide variation among them. Pain is usually measured by a descriptive ordinal scale (Keele 1948) using the adjectives 'severe', 'moderate', 'mild' or 'none' although this has been shown to be an inaccurate method compared with a visual analogue scale (Huskisson 1974). In the latter method a $10 \mathrm{~cm}$ line, representing the whole range from no pain to severe pain, is marked with a cross on the appropriate site by the patient.

Hip movement can be measured as the sum of the arcs of movement in all three planes, by calculating Gade's index (Harris 1969), or by assessing functional activities which are known to require a good range of movement.

There is no unanimity in the variables chosen to assess functional activity (Fig. 1), nor are all the variables applicable to all patients; for example, car driving by patients who do not hold a driving licence or stairclimbing by patients who live in a bungalow.

Charnley (1972) recognised that the results of hip arthroplasty in two groups of patients should be compared only if the groups are similar in other respects and he described three categories: (A) patients with monoartic-

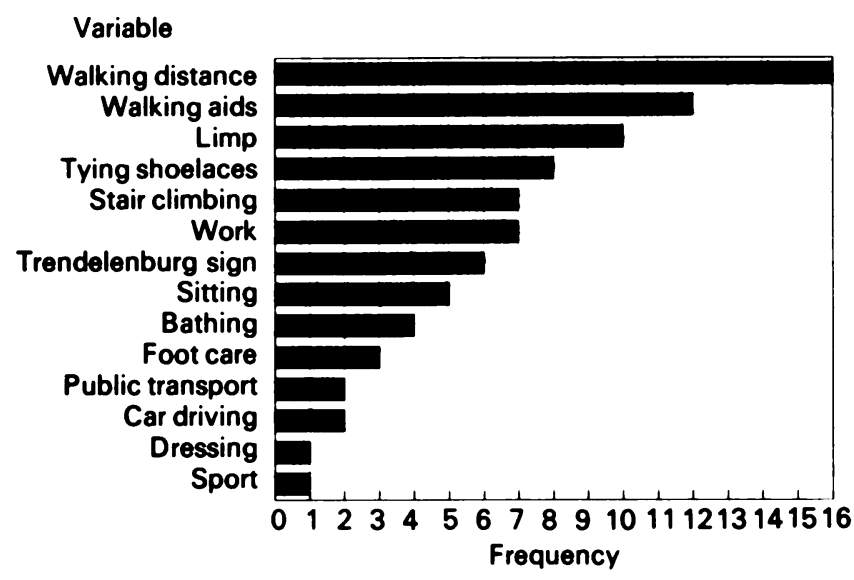

Fig. 1

Variables measured to assess hip function and the frequency of their use in 19 hip scores. 
Table I. Methods of hip scoring to show the different variables used in each score and associated weightings. Shepherd's score also measured the patients' opinion of the operation

\begin{tabular}{|c|c|c|c|c|c|}
\hline Score & Pain & Movement & Function & $\begin{array}{l}\text { Absence of } \\
\text { deformity }\end{array}$ & $\begin{array}{l}\text { Radiological } \\
\text { signs }\end{array}$ \\
\hline \multicolumn{6}{|l|}{ Numerical scores (variables measured separately) } \\
\hline Gade (1947) & + & + & + & & \\
\hline Danielsson (1964) & + & + & + & & \\
\hline Charnley (1972) & + & + & + & & \\
\hline $\begin{array}{l}\text { University College of Los Angeles (Dutton et } \\
\text { al 1982) }\end{array}$ & + & & + & & \\
\hline \multicolumn{6}{|l|}{ Numerical scores (variables summated, percentages) } \\
\hline Ferguson and Howorth (1931) & & 100 & & & \\
\hline Judet and Judet (1952) & 33 & 33 & 33 & & \\
\hline Merle d'Aubigné and Postel (1954) & 40 & 20 & 40 & & \\
\hline Stinchfield, Cooperman and Shea (1957) & 33 & 33 & 33 & & \\
\hline Larson (1963) & 40 & 10 & 45 & 5 & \\
\hline Lazansky (1967) & 27 & 39 & 23 & 11 & \\
\hline Harris (1969) & 44 & 5 & 47 & 4 & \\
\hline Andersson (1972) & 33 & 33 & 33 & & \\
\hline McKee and Chen (1973) & 33 & & 66 & & \\
\hline HSS (Pellici et al 1985) & 17 & 17 & 33 & & 33 \\
\hline Mayo (Kavanagh and Fitzgerald 1985) & 40 & & 40 & & 20 \\
\hline \multicolumn{6}{|l|}{ Descriptive scores } \\
\hline Shepherd (1954) & + & + & + & & \\
\hline $\begin{array}{l}\text { American Academy of Orthopaedic Surgeons } \\
\text { (Goodwin 1968) }\end{array}$ & + & + & + & & \\
\hline Ring (1968) & + & + & + & & \\
\hline Öhman, Bjorkegren and Fahlstrom (1969) & + & + & + & & \\
\hline
\end{tabular}

ular disease, (B) those with bilateral disease, and (C) those with other diseases such as rheumatoid arthritis or angina pectoris, which limited their functional activity.

Andersson (1972) compared several hip scores in a group of patients who had undergone Austin Moore hemiarthroplasty but he used no statistical methods to test the observed differences. Callaghan et al (1990) demonstrated statistically significant differences between various scores, the Hospital for Special Surgery (HSS) score being the most optimistic and the Merle d'Aubigné score the most pessimistic. Classifying the patients according to Charnley (A, B or C) significantly affected these ratings. Kavanagh and Fitzgerald (1985) compared the Mayo hip score (which includes radiological evidence of prosthetic loosening) and the Harris hip score and showed a statistically significant difference between them. Galante (1985) criticised the inclusion of radiological signs of loosening in a hip score because of the lack of agreed criteria for loosening. Johnston et al (1990) proposed standard terms for the description of clinical and radiological variables, but the number of variables was large and the resulting proforma was unwieldy. Although it was suggested that selected variables could be used, no guidance was given as to which were the most appropriate.

Our aim was to compare various methods of hip scoring and individual variables to identify common factors which could be used as a basis for comparison.

\section{MATERIAL AND METHODS}

Clinical data were recorded for 41 patients who had had 47 Ring hip arthroplasties 15 to 20 years previously (mean 19.6). A proforma was designed so that 13 different

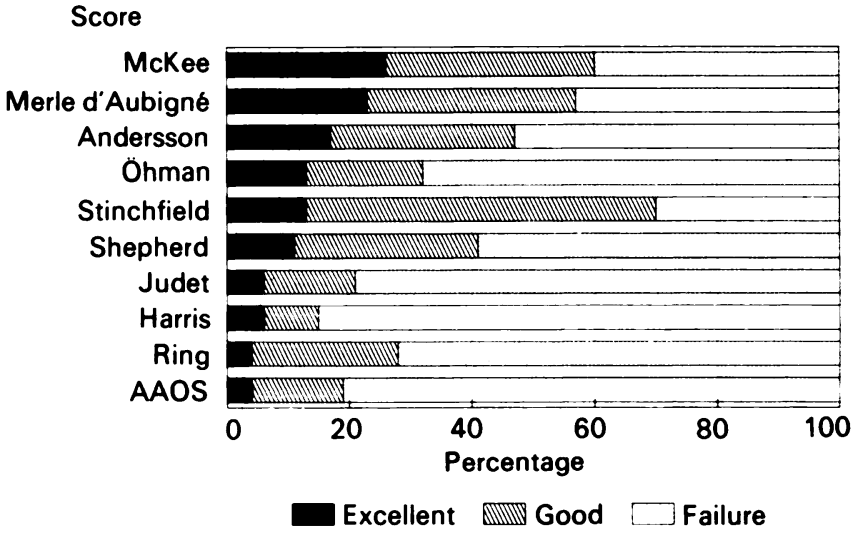

Fig. 2

Results of ten hip scores applied to 47 arthroplasties. All the scores give an overall descriptive value in terms of excellent, good or a failure. They are ranked in order of increasing percentage of excellent results.

hip scores could be calculated for each arthroplasty using a spreadsheet package (Lotus 123) on an IBM-compatible computer. The clinical results for this group of patients have already been published (Bryant, Mollan and Nixon 1991).

To study individual variables rather than overall scores a larger number of variables was needed; data were therefore collected from 226 patients who had had 256 Richards International (Smith and Nephew Richards Inc, Memphis, Tennessee) total hip arthroplasties one year previously. These patients were assessed using the Harris hip score and the individual variables were evaluated statistically by the Superior Performance Software Systems (Version X) (SPSS Inc, Chicago, Illinois) package on the ICL S39 L80 computer at Queen's 
University, Belfast. Multivariate statistical analysis was used to identify relationships between the individual variables.

\section{RESULTS}

There was a wide discrepancy between scores that gave the overall result as excellent, good or failure (Fig. 2). For 36 of the 47 arthroplasties the scores differed only between good and excellent or between failure and good, but for the other 11 arthroplasties the results had a wider spread, being characterised as excellent, good or failure depending on which score had been used. A percentage maximum score was calculated for each hip score so that the results could be compared (Fig. 3).

There was more agreement among the scores giving numerical rather than descriptive values. The $95 \%$ confidence limits for the Larson, the Harris, the McKee, the Andersson, the HSS, the Mayo and the Stinchfield scores overlapped. The $95 \%$ confidence limits for the Judet and the Merle d'Aubigné scores also overlapped, but they were significantly lower.

Spearman correlation coefficients showed a poor correlation between scores recorded in terms of excellent, good or failure (Table II) but were higher when results were expressed numerically. For example, the Judet and Merle d'Aubigné scores had a correlation of $73 \%$ when results were expressed in terms of excellent, good or failure but $94 \%$ when they were expressed as percentages of maximum numerical score. Correlation coefficients were also calculated for 19 individual variables, and most of these coefficients were small and not significant (Table III). Pain correlated very poorly with every other variable, indicating that it was an independent variable. Walking distance, the use of walking aids, and return to work showed the highest correlations with the largest number of other variables which measure functional activity.

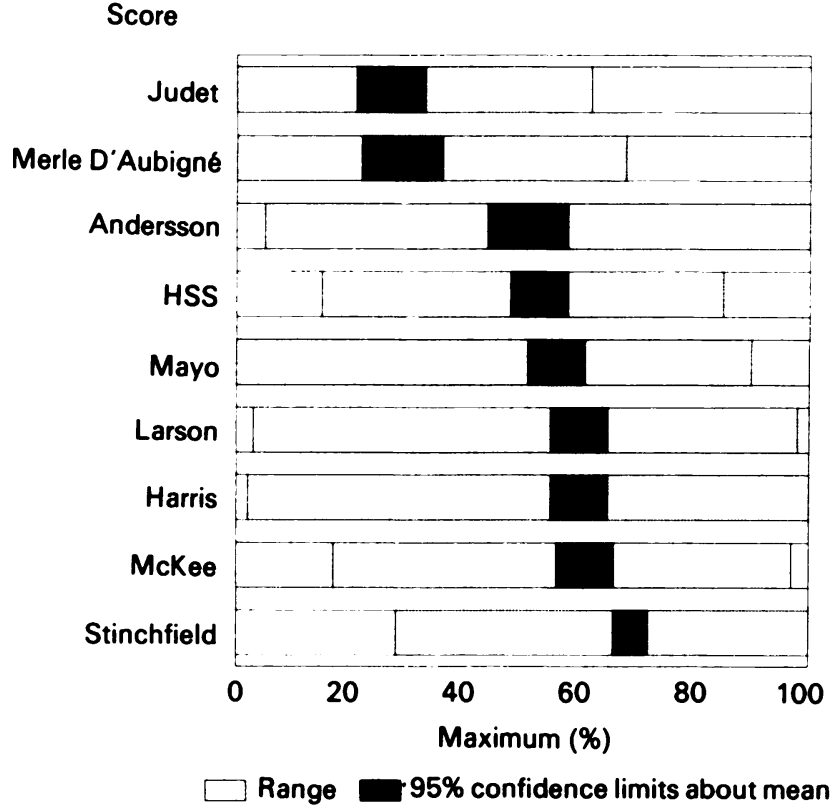

Fig. 3

about mean

Results of nine hip scores applied to 47 arthroplasties expressed as a percentage of the maximum numerical value. For each score its range, mean and $95 \%$ confidence limits about the mean are plotted.

There was a striking correlation between the several measures of hip movement. The correlation between Gade's index and the sum total of all arcs of movement was $98 \%$; between Gade's index and the flexion arc $93 \%$; and between the flexion arc and the sum total $90 \%$ (all highly significant, $\mathrm{p}<0.001$ ).

In the larger group of patients with Richards International hip arthroplasties, factor analysis was used to identify those variables that were closely related. Three factors were identified: the first contained the variables walking distance, stair-climbing, use of public transport, use of walking aids, limp, sitting and tying shoelaces; the second contained the variables of movement and fixed

Table II. Spearman correlation coefficients $(\times 100)$ calculated for hip scores expressed in terms of excellent, good or failure $(A)$ and as a percentage of maximum numerical score (B). All values have a significance level of $p<0.001$

\begin{tabular}{|c|c|c|c|c|c|c|c|c|}
\hline & Spean & $\operatorname{man} c 0$ & rrelati & on coeffi & icient ( & $(\times 100)$ & & \\
\hline $\begin{array}{l}\text { A } \\
\text { Merle d'Aubigné (d'A) } \\
\text { Harris (Har) } \\
\text { McKee (McK) } \\
\text { Ring } \\
\text { Öhmman } \\
\text { Andersson (And) } \\
\text { AAOS } \\
\text { Shepherd (Shep) } \\
\text { Stinchfield }\end{array}$ & $\begin{array}{l}73 \\
70 \\
46 \\
44 \\
55 \\
64 \\
59 \\
49 \\
55 \\
\text { Judet }\end{array}$ & $\begin{array}{l}53 \\
53 \\
47 \\
51 \\
66 \\
45 \\
52 \\
65 \\
\text { d.A }\end{array}$ & $\begin{array}{l}49 \\
59 \\
73 \\
64 \\
60 \\
64 \\
45 \\
\text { Har }\end{array}$ & $\begin{array}{l}60 \\
56 \\
71 \\
48 \\
65 \\
66 \\
\text { McK }\end{array}$ & $\begin{array}{l}72 \\
71 \\
69 \\
85 \\
52 \\
\text { Ring }\end{array}$ & $\begin{array}{l}79 \\
66 \\
84 \\
53 \\
\text { Öhman }\end{array}$ & $\begin{array}{c}61 \\
77 \\
67 \\
n \text { And }\end{array}$ & $\begin{array}{l}60 \\
49 \quad 49 \\
\text { AAOS Shep }\end{array}$ \\
\hline $\begin{array}{l}\text { B } \\
\text { Merle d'Aubigné } \\
\text { Larson (Lar) } \\
\text { Harris } \\
\text { McKee } \\
\text { Andersson } \\
\text { HSS } \\
\text { Mayo } \\
\text { Stinchfield }\end{array}$ & $\begin{array}{l}94 \\
83 \\
82 \\
67 \\
76 \\
83 \\
79 \\
89 \\
\text { Judet }\end{array}$ & $\begin{array}{l}82 \\
82 \\
73 \\
71 \\
78 \\
82 \\
85 \\
\text { d'A }^{5}\end{array}$ & $\begin{array}{l}95 \\
84 \\
89 \\
94 \\
93 \\
90 \\
\text { Lar }\end{array}$ & $\begin{array}{l}83 \\
83 \\
87 \\
89 \\
89 \\
\text { Har }\end{array}$ & $\begin{array}{l}84 \\
79 \\
71 \\
75 \\
\text { McK }\end{array}$ & $\begin{array}{l}91 \\
75 \\
85 \\
\text { And }\end{array}$ & $\begin{array}{l}86 \\
93 \\
\text { HSS }\end{array}$ & $\begin{array}{l}86 \\
\text { Mayo }\end{array}$ \\
\hline
\end{tabular}


Table III. Spearman correlation coefficients $(\times 100)$ calculated for the 19 variables

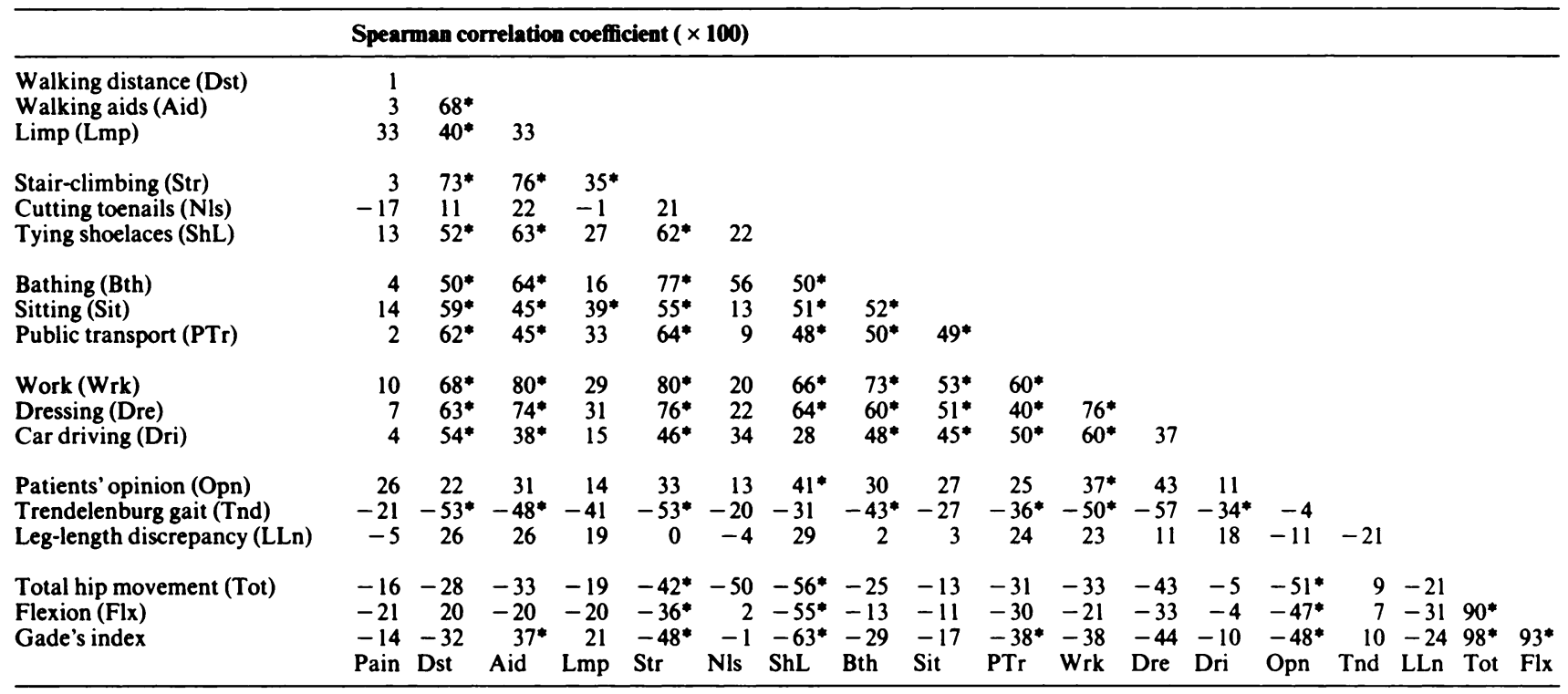

$* \mathrm{p}<0.01$

deformity; and the third contained the variable pain (Table IV).

\section{DISCUSSION}

The measured outcome of a hip arthroplasty depends upon the hip score used to measure that outcome, as has been reported by Andersson (1972) and by Callaghan et al (1990). We found large differences between the results of those scores which used descriptive terms such as excellent, good or failure and better correlations between numerical scores. There appeared, however, to be a considerable difference between the Judet and Merle d'Aubigne scores on the one hand, and the Larson, Harris, McKee, Andersson, HSS, Mayo and Stinchfield scores on the other. The explanation is that the Judet and Merle d'Aubigné scores divide the total points equally between pain, movement and functional activity whereas in the other systems pain has proportionally more effect.

Among the different variables, three 'core' factors were identified. The first is the group of variables which describes functional activity, the best single measure being the walking distance. The second describes hip movement and deformity. The only measure necessary for assessment of movement proved to be simple hip flexion, since it correlated well with the more complex Gade's index and with the total range of movement. The third factor is pain; this correlated poorly with every other variable. We recognise that this may not be due to a true lack of association, but may only reflect the difficulty of measuring pain reliably.

The essential variables for measurement appear to be walking distance, hip flexion and pain. Measurements of more than these three variables add little further information about the outcome of hip arthroplasty. We
Table IV. Factor analysis used to group the ten variables measured in the Harris hip score according to weightings based on correlation coefficients

\begin{tabular}{lrrr}
\hline & \multicolumn{3}{l}{ Factor* } \\
\cline { 2 - 4 } Variable & 1 & \multicolumn{1}{l}{2} & \multicolumn{1}{l}{3} \\
\hline Cumulative variance & $40 \%$ & $52 \%$ & $62 \%$ \\
Walking distance & 82 & -2 & 2 \\
Stair-climbing & 79 & 13 & 21 \\
Public transport & 78 & -2 & -11 \\
Walking aids & 74 & 15 & -4 \\
Limp & 70 & 33 & 18 \\
Sitting & 60 & 4 & 36 \\
Tying shoelaces & 53 & 37 & 30 \\
Total hip movement & 11 & 83 & 21 \\
Deformity & 5 & 67 & -31 \\
Pain & 6 & -2 & 86 \\
\hline
\end{tabular}

* the first factor accounted for $40 \%$ of the total variance for the ten variables, the first two factors for $52 \%$ of the total variance and the first three for $62 \%$ of the total variance. Further factorisation accounted for proportionally less of the total variance

recommend that these three variables should be recorded separately; numerical scores which combine them are arbitrary and without scientific foundation. We therefore suggest that the 'three factor' hip score be used to assess the results of hip arthroplasty.

No benefits in any form have been received or will be received from a commercial party related directly or indirectly to the subject of this article.

\section{REFERENCES}

Andersson G. Hip assessment : a comparison of nine different methods. J Bone Joint Surg [ Br] 1972; 54-B:621-5.

Bryant MJ, Mollan RAB, Nixon JR. Survivorship analysis of the Ring hip arthroplasty. J Arthroplasty $1991 ; 6$ :s5-s10. 
Callaghan JJ, Dysart SH, Savory CG, Hopkinson WJ. Assessing the results of hip replacement: a comparison of five different rating systems. J Bone Joint Surg [ Br] 1990; 72-B:1008-9.

Charnley J. The long-term results of low-friction arthroplasty of the hip performed as a primary intervention. J Bone Joint Surg [Br] 1972; 54-B:61-76.

Danielsson LG. Incidence and prognosis of coxarthrosis. Acta Orthop Scand 1964; Suppl. 66.

Dutton RO, Amstutz HC, Thomas BJ, Hedley AK. Tharies surface replacement for osteonecrosis of the femoral head. $J$ Bone Joint Surg [ Am] 1982; 64-A :1225-37.

Ferguson AB, Howorth MB. Slipping of upper femoral epiphysis: study of 70 cases. JAMA 1931; 97:1867-72.

Gade HG. A contribution to the surgical treatment of osteoarthritis of the hip joint: a clinical study. Acta Chir Scand 1947; 120:37-45.

Galante J. Editorial. The need for a standardized system for evaluating results of total hip surgery. J Bone Joint Surg [Am] 1985; 67-A: 511-2.

Goodwin RA. The Austin Moore prosthesis in fresh femoral neck fractures. Am J Orth Surg 1968; 10:40-3.

Harris WH. Traumatic arthritis of the hip after dislocation and acetabular fractures: treatment by mold arthroplasty. J Bone Joint Surg $[\mathrm{Am}] 1969 ; 51-\mathrm{A}: 737-55$.

Huskisson EC. Measurement of pain. Lancet 1974;ii:1127-31.

Johnston RC, Fitzgerald RH, Harris WH, et al. Clinical and radiographic evaluation of total hip replacement: a standard system of terminology for reporting results. J Bone Joint Surg [ Am] $1990 ; 72-A: 161-8$.
Judet R, Judet J. Technique and results with acrylic femoral head prosthesis. J Bone Joint Surg [ Br] 1952; 34-B:173-80.

Kavanagh BF, Fitzgerald RH Jr. Clinical and roentgenographic assessment of total hip arthroplasty: a new hip score. Clin Orthop $1985 ; 193: 133-40$.

Keele KD. The pain chart. Lancet 1948; 2:6-8.

Larson CB. Rating scale for hip disabilities. Clin Orthop 1963; 31 :8593.

Lazansky MG. A method for grading hips. J Bone Joint Surg [ Br] 1967; 49-B :644-51.

McKee GK, Chen SC. The statistics of the McKee-Farrar method of total hip replacement. Clin Orthop 1973; 95:26-33.

Merle d'Aubigné R, Postel M. Functional results of hip arthroplasty with acrylic prosthesis. J Bone Joint Surg [Am] 1954; 36-A: 451-75.

Öhman U, Björkegren NA, Fahlström G. Fracture of the femoral neck: a five year follow-up. Acta Chir Scand 1969; $135: 27-42$.

Pellici PM, Wilson PD, Sledge CB, et al. Long-term results of revision total hip replacement: a follow-up report. J Bone Joint Surg [ Am] 1985; 67-A :513-6.

Ring PA. Complete replacement arthroplasty of the hip by the Ring prosthesis. J Bone Joint Surg [Br] 1968; 50-B:720-31.

Shepherd MM. Assessment of function after arthroplasty of the hip. $J$ Bone Joint Surg [ Br] 1954; 36-B:354-63.

Stinchfield FE, Cooperman B, Shea CE. Replacement of the femoral head by Judet or Austin Moore prosthesis. J Bone Joint Surg [ Am] $1957 ; 39-A: 1043-58$. 